\title{
IDEIAS E LEGISLAÇÃO SOBRE FAMÍLIA NA UNIÃO SOVIÉTICA: AVANÇOS, RETROCESSOS E INSPIRAÇÕES
}

\author{
GOLDMAN, Wendy. (2014). Mulher, Estado e revolução: política familiar e vida \\ social soviéticas, 1917-1936. 1. ed., São Paulo: Boitempo: Iskra Edições.
}

Em 1993, foi publicado nos Estados Unidos o livro Mulher, Estado e revolução: política familiar e vida social soviéticas, 1917-1936, escrito por Wendy Goldman. A obra está organizada em oito capítulos, mais a conclusão, que tratam da visão bolchevique sobre o amor e a emancipação das mulheres, o dilema das crianças sem lar e da criação socializada, o direito ao divórcio e a relação com a economia, a vida camponesa, o direito ao aborto e as mudanças relacionadas à valorização da família. A autora mantém uma preocupação em contextualizar os fatos, trazer dados comparáveis e reproduzir discussões da União Soviética (URSS) sobre temas controversos que ajudam o leitor a se situar e compreender as ideias que estavam sendo propostas. Goldman é uma historiadora americana e atualmente leciona no Departamento de História da Carnegie Mellon University. Além deste livro, que ganhou o Berkshire Book Award Conference em 1994, a autora escreveu outras obras que tratam da Rússia e da URSS. Em 2014, Mulher, Estado e revolução foi publicado no Brasil pela editora Boitempo, sendo traduzido por Natália Angyalossi Alfonso.

No prefácio da edição brasileira, escrito em dezembro de 2013, Goldman explica que a partir da combinação de história política e social ela traz as lições de juristas e revolucionários, e as ideias e lutas das mulheres trabalhadoras e camponesas. Em 2017, data em que se completam 100 anos da Revolução Russa de 1917, é curioso perceber o quanto algumas questões discutidas no início do século XX na URSS, como a privatização das famílias ${ }^{1}$, ainda são atuais. A obra de Goldman poderia

1 A expressão privatização das famílias também é utilizada pela literatura com o termo "familismo", e indica uma situação na qual as famílias são as principais responsáveis pelo bem-estar social dos seus integrantes ao mesmo tempo em que há pouco apoio do Estado para a manutenção das pessoas. ser analisada por diferentes perspectivas, porém opto por destacar a questão da família e, mais especificamente, das tentativas da URSS de "desprivatizar" as famílias. Atualmente, os debates sobre família ocorrem como se a forma como as pessoas vivem e se organizam socialmente não tivesse nenhuma relação com a política ou a economia. O livro de Goldman traz esse ponto de forma contundente e contribui para a reflexão de que as leis que interferem nas famílias e em suas relações provocam consequências relevantes para a vida econômica e política de um país, e no caso soviético isso ficou muito claro.

Diversos fatores contribuíram para que nossa imaginação política passasse por um processo de atrofiamento no qual somos, muitas vezes, incapazes de conceber formas alternativas de organização da vida social e socialização dos trabalhos domésticos e de cuidado com as crianças. A maioria dos países ocidentais, como Estados Unidos, França e Brasil, são marcados pelo modo de produção capitalista - com as relações mercantis exercendo papel central na vida cotidiana - e pela organização das pessoas em núcleos familiares individualizados. Esses aspectos, juntamente com o colapso de países que tentaram se organizar de forma econômica e socialmente diferentes, trazem a ideia de que não seria possível viver sob um regime diferente do capitalismo, e de que não haveria a possibilidade de as pessoas se organizarem em suas vidas privadas a não ser através das unidades familiares. Nesse contexto, a obra de Goldman ganha relevância na medida em que traz para o debate outras possibilidades de organização social - que não deram certo na URSS, mas que podem servir de inspiração para novas propostas.

O primeiro e mais longo capítulo se concentra na discussão protagonizada pelos teóricos soviéticos sobre

\section{Rayani Mariano}

Doutoranda em Ciência Política - Universidade de Brasília (UnB).

E-mail: rayanimar@gmail.com 
a situação das mulheres, o casamento, a família e as crianças. Nele são apresentados os ideais relacionados à igualdade e libertação das mulheres, à extinção da família e à socialização do cuidado com as crianças e dos trabalhos domésticos. A trajetória feita por Goldman nos capítulos seguintes mostra muito claramente que só os ideais não foram suficientes, que não basta afirmar na legislação que homens e mulheres são iguais ou que o Estado deve assumir a responsabilidade pelas crianças, é preciso ter condições práticas para que os ideais se concretizem.

$\mathrm{Na}$ URSS e na maior parte dos países atualmente, as mulheres são as principais responsáveis por realizar o trabalho doméstico dentro das famílias, e esse fato influencia diretamente nas suas possibilidades de trabalho, lazer, tempo. Hirata e Kergoat (2007: 599) definem a divisão sexual do trabalho como "a forma de divisão do trabalho social decorrente das relações sociais entre os sexos; mais do que isso, é um fator prioritário para a sobrevivência da relação social entre os sexos". Entre as características dessa divisão estariam a designação dos homens à esfera produtiva e das mulheres à esfera reprodutiva, com as funções de maior valor na sociedade reservadas aos indivíduos do sexo masculino. Essa questão perpassa várias das temáticas discutidas no livro, e muitas vezes é deixada de lado no pensamento bolchevique em função da própria preferência dos soviéticos, ressaltada por Goldman, por levar o trabalho doméstico para a esfera pública ao invés de fomentar a divisão igualitária entre os sexos dentro das casas.

Em 1918, um ano após a revolução russa, foi ratificado o Código do Casamento, da Família e da Tutela que refletiu uma visão revolucionária das relações sociais ancorada na igualdade das mulheres e no "definhamento" da família. Os bolcheviques acreditavam que um dos problemas criados pelo capitalismo e intensificado com a industrialização se relacionava à dificuldade das mulheres em entrarem no mercado de trabalho e, ao mesmo tempo, terem que se responsabilizar pelas suas famílias, realizando os trabalhos domésticos e o cuidado das crianças. Para os bolcheviques, só o socialismo poderia resolver esse dilema através da transferência do trabalho doméstico para a esfera pública. As tarefas que as mulheres realizavam em suas casas passariam a ser desempenhadas por trabalhadores assalariados em refeitórios, lavanderias e creches comunitários. Dessa forma, as mulheres poderiam ser educadas e receber salários igualitários, buscar seus objetivos pessoais, e o casamento se tornaria desnecessário. Os bolcheviques esperavam que a família, assim como a lei e o Estado, desaparecessem, ou seja, com o tempo, as leis não seriam mais necessárias e as pessoas também não viveriam mais em núcleos familiares.

A autora explica que, apesar da aparente simplicidade das ideias bolcheviques para solucionar a situação desigual das mulheres no mercado de trabalho, nas famílias etc., elas se baseavam em complexas suposições. Um dos problemas se relaciona ao fato de que os bolcheviques defenderam que o trabalho doméstico fosse levado à esfera pública, mas não provocaram os homens a dividirem essas atividades com as mulheres. Outro seria a tensão entre o indivíduo e a coletividade ou o Estado. Apesar de os bolcheviques defenderem a liberdade individual e a eliminação da autoridade religiosa e estatal, o fato de o Estado concentrar a responsabilidade pela criação das crianças promoveria um grande aumento do papel social do Estado ao excluir campos intermediários como a família. As críticas que Goldman faz às ideias bolcheviques são extremamente pertinentes e estão no centro das discussões feministas atuais sobre cuidado, porém a autora não aprofunda muito nessas questões, o que poderia ter enriquecido a discussão presente no livro ${ }^{2}$.

Apesar das ideias revolucionárias, as dificuldades reais da União Soviética impediram que os planos fossem efetivados com sucesso. A Primeira Guerra Mundial, a guerra civil, a fome de 1921 e as epidemias ocasionaram milhares de mortes e o desmoronamento das famílias. Como consequência, o número de crianças sem lar - os bresprizorniki - aumentou significativamente. Goldman relata de forma minuciosa como era a vida de milhares de crianças que ficaram órfãs ou que tinham famílias desestruturadas e acabavam indo viver na rua e em estações de trem. Os lares que recebiam essas crianças não tinham condições de cuidar delas, não havia comida suficiente, roupas, remédios, funcionários.

\footnotetext{
2 Quando o livro foi publicado nos Estados Unidos, em 1993, as discussões feministas sobre cuidado já faziam parte do debate, com as teóricas "maternalistas" buscando positivar as atividades desenvolvidas pelas mulheres no espaço doméstico. Porém, é importante ponderar que essa discussão sofreu mudanças ao longo do tempo, e atualmente teóricas como Joan Tronto (2013) trazem o cuidado como central para se pensar as sociedades e a democracia. Para uma análise mais detalhada, cf. Biroli (2015).
} 
Diante das dificuldades econômicas e sociais que o país enfrentava, agravadas pela escassez de alimentos, foi proposta e implementada a Nova Política Econômica (NEP), em 1921. Goldman relata que, a princípio, era uma medida simples que visava substituir a prática de confisco de grãos dos camponeses para alimentar as cidades e o exército por um imposto fixo e permitir que os camponeses comercializassem o excedente de sua produção. Um dos méritos do livro, que pode ser observado quando ela trata das consequências da NEP e em outros momentos, é a articulação que a autora consegue fazer entre a situação econômica do país e as consequências para a vida das mulheres. No caso específico da NEP, houve redução dos serviços orientados às mulheres e crianças, como creches e orfanatos, e ocorreu um aumento do desemprego feminino. Foi nesse contexto - de precarização da vida das mulheres e aumento de crianças sem lar - que as ideias progressistas de responsabilização do Estado pelas crianças e socialização do cuidado perderam força e foram sendo progressivamente substituídas pelo incentivo às famílias para criarem seus próprios filhos e pela revogação da lei que proibia a adoção. Goldman explica que o custo para transferir o trabalho da esfera doméstica para a pública era extremamente alto, enquanto o trabalho das mulheres não tinha custo nenhum para o Estado.

Outro tema que despertou intenso debate na URSS e dificuldades práticas foi a união livre e o divórcio. Goldman destaca que os bolcheviques defendiam que a liberdade de se divorciar tinha relação direta com a própria liberdade dos indivíduos, e era especialmente importante para as mulheres. O Código da Família de 1918, ao facilitar o divórcio, contribuiu para que a prática aumentasse e trouxe consequências relevantes principalmente para as mulheres de classes mais baixas e para as pessoas que viviam no meio rural (a maior parte da população). Além disso, o aumento no número de divórcios trouxe o desafio de se enfrentar o problema das pensões alimentícias. Apesar de as mulheres terem entrado no mercado de trabalho, elas ocupavam os postos mais precários $^{3} \mathrm{e}$ muitas vezes dependiam economicamente dos maridos, e a necessidade da pensão demonstrava que o Estado não conseguia cumprir o papel de fornecer serviços sociais

3 Segundo Goldman (2014: 150), as mulheres eram a maioria da força trabalhadora nos ramos de alimentação (75\%), costura (74\%), saúde $(63 \%)$ e indústria têxtil $(60 \%)$. para as mulheres e crianças e indicava a escassez de opções fora das famílias.

No início da década de 1920, os juristas tentaram reformar o Código da Família, e apresentaram um projeto para ser debatido pela população. Goldman narra com bastante detalhe as discussões relacionadas ao Código, as mudanças feitas desde a primeira proposta, e as diferentes posições - inclusive dos que julgavam que as leis deveriam desaparecer e que não fazia sentido uma lei sobre o assunto. Os debates foram acirrados porque a questão do divórcio se relacionava de forma muito direta com o modo de vida camponês. Ao contrário da classe trabalhadora urbana, os camponeses não trabalhavam por salários individuais. Eles viviam juntos nas antigas instituições do lar, chamadas de $d v o r$, e consumiam de forma coletiva o que produziam. Goldman (2014: 189) explica que o dvor "era uma unidade baseada em familiares, patriarcal e local, composta por um ou mais grupos de famílias". Essa organização colidia com as leis progressistas relativas ao divórcio, pois quando as mulheres demandavam a pensão, o pagamento provinha da produção ou bens de todo o $d v o r$ e impactava a vida não só do ex-cônjuge. Essa situação gerou problemas difíceis de serem solucionados que eram decididos de forma individual pelos tribunais.

Outro assunto discutido por Goldman se relaciona com os direitos reprodutivos. O Código Penal de 1885 indicava o aborto como um "ato premeditado de assassinato" e estabelecia punição tanto para as mulheres quanto para quem realizasse o procedimento. Após a Revolução, em 1920, o aborto foi legalizado, podendo ser realizado nos hospitais de forma gratuita e tornando a URSS o primeiro país a garantir a interrupção da gestação. Porém, o decreto que legalizou o aborto não o reconhecia como direito das mulheres e Goldman retrata que, na prática, o acesso não era tão fácil - já que devido à grande demanda, foram estabelecidos critérios para delimitar quais mulheres teriam prioridade $-\mathrm{e}$ o procedimento era realizado sem anestesia e de forma extremamente dolorosa, levando algumas a preferirem realizá-lo por métodos alternativos e menos seguros. Goldman ressalta que a industrialização, a urbanização e a coletivização cresceram junto com o aumento do número de abortos legais e, provavelmente, dos ilegais.

Em 1936, um decreto tornou o aborto ilegal novamente, ato que se adequava à guinada conservadora 
da política familiar da URSS. A autora explica que as evidências indicam que a proibição do aborto foi motivada pela preocupação com a diminuição das taxas de natalidade, mas que essa proibição conseguiu um resultado apenas a curto prazo, e que já em 1940, a taxa de natalidade voltou aos níveis anteriores de 1935. No período analisado por Goldman, a política sobre a família passou de uma visão centrada na liberdade individual e exclusão da família, para uma política ancorada em seu fortalecimento. Teóricos que antes defendiam a emancipação das mulheres e a responsabilidade do Estado no cuidado das crianças passaram a enaltecer a maternidade. Os fatos que se seguiram e as ideias narradas por Goldman lembram a retomada da história da "invenção" e valorização da maternidade contada por Badinter (1985) ${ }^{4}$.

Goldman explica que o Estado passou a enfatizar cada vez mais a responsabilidade familiar quando começou a ficar mais clara a relação entre divórcio, mães solteiras, o não pagamento de pensões alimentícias após os divórcios e o problema das crianças sem lar. Além disso, o fator macroeconômico também foi uma das causas: a entrada das mulheres na força de trabalho acabou contribuindo para sua dependência em relação à família, porque entre 1928 e 1932, os salários reais caíram 49\%, possibilitando que o Estado se aproveitasse da produção do casal pelo preço de um trabalhador.

Em 1936, foi criada uma nova lei que aumentava a pena para o não pagamento de pensão alimentícia, dificultava o divórcio, proibia o aborto e aumentava o número de creches. $\mathrm{O}$ alto número de crianças sem lar - que ao longo dos anos foram influenciando o Estado a abandonar a ideia de uma criação coletiva das crianças, as dificuldades econômicas, o peso das tradições camponesas, enfim, o contexto soviético foram fatores fundamentais para as mudanças na legislação relacionada à família. No final da década de 1930, Goldman relata que teóricos que exerceram papel relevante na formulação do Código da Família foram executados ou internados em instituições psiquiátricas. E em 1944, o Édito sobre a Família promoveu mudanças significativas nas legislações anteriores, retirando o reconhecimento

4 Badinter (1985) analisa o caso francês, e afirma que nas últimas décadas do século XVIII há uma mudança de mentalidade na qual a imagem, a importância e o papel das mães se transformam. Com a proliferação de publicações recomendando às mulheres que amamentem os filhos e que cuidem deles pessoalmente vai surgindo o mito do instinto materno. do casamento de facto, proibindo julgamentos para reconhecimento de paternidade, e transferindo o divórcio de volta para os tribunais.

O livro de Goldman analisa um período específico da URSS, mas as ideias trazidas são atuais e capazes de enriquecer os debates e as produções feministas contemporâneas. Todos os temas discutidos se relacionam de alguma forma com a família, como o trabalho das mulheres - e sua desvalorização, o cuidado das crianças, o trabalho doméstico, os direitos reprodutivos. Quando observamos o contexto político brasileiro recente é possível perceber o quanto a suposta "defesa da família" vem ganhando destaque em discursos de parlamentares e projetos de lei, como o Estatuto da Família (PL 6583/13). Há no caso brasileiro uma tentativa de parlamentares conservadores de reforçar a família tradicional, heterossexual, monogâmica e com papeis de gênero estabelecidos. Esse movimento conservador de defesa da família é o oposto do que ocorreu na URSS nos anos subsequentes à Revolução. E a proposta daquele país de transferir para a esfera pública os trabalhos realizados dentro das famílias não está colocada como prioritária no debate público brasileiro.

Se pensarmos no contexto brasileiro hoje, também podemos afirmar que possuímos problemas semelhantes aos da URSS. Não possuímos creches para todas as crianças; não conseguimos transferir serviços realizados prioritariamente por mulheres no espaço privado de suas casas - como alimentação e lavanderia - para a esfera pública; não conseguimos igualar os salários das mulheres aos dos homens. Essas questões - que são centrais para enfrentar as desigualdades de gênero - não possuem soluções simples, e muitas vezes não há sequer tentativas de enfrentá-las porque predomina a ideia de que cada família tem que ser responsável por si mesma. Uma das principais qualidades do livro Mulher, Estado e revolução é mostrar que há alternativas à privatização das famílias e que elas inclusive foram experimentadas.

\section{Referências bibliográficas}

BADINTER, Elisabeth. (1985). Um amor conquistado: o mito do amor materno. Rio de Janeiro: Nova Fronteira. 
BIROLI, Flávia. (2015). "Responsabilidades, cuidado e democracia". Revista Brasileira de Ciência Política, n. 18: p. 81-117, set-dez.

HIRATA, Helena; KERGOAT, Danièle. (2007) "Novas configurações da divisão sexual do trabalho". Cadernos de Pesquisa, n. 37, 132: p. 595-609, set-dez.

TRONTO, Joan C. (2013) Caring democracy: markets, equality, and justice. Nova York e Londres: New York University Press.

Recebido em: 15/03/2017.

Aceito: 30/06/2017. 